\title{
Optimal and worst examination strategies for COVID-19
}

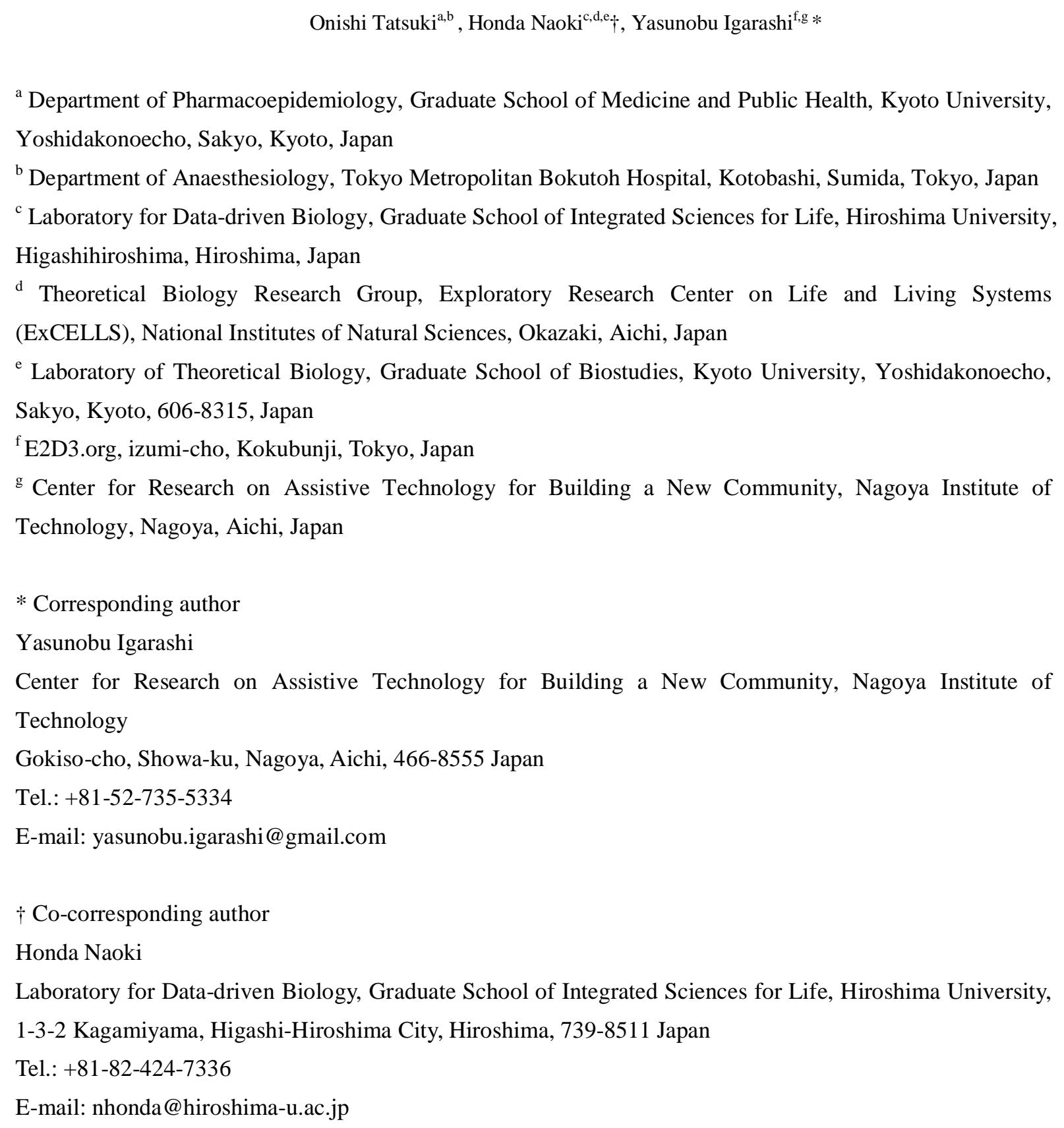




\section{$34 \quad$ Abstract}

Coronavirus disease 2019 (COVID-19) is an emerging threat to the whole world, and every government is seeking an optimal solution. However, none of them have succeeded, and they have only provided series of natural experiments. Although simulation studies seem to be helpful, there is no model that addresses the how much testing to be conducted to minimise the emerging infectious disease outbreaks. In this study, we develop a testing susceptible, infectious, exposed, recovered, and dead (testing-SEIRD) model using two discrete populations inside and outside hospitals. The populations that tested positive were isolated. Through the simulations, we examined the infectious spread represented by the number of cumulative deaths, hospitalisations, and positive tests, depending on examination strategies, testing characteristics, and hospitalisation capacity. We found all-or-none responses of either expansion or extinction of the infectious spreads, depending on the rates of follow-up and mass testing, which represent testing the people identified as close contacts with infected patients using follow-up surveys and people with symptoms, respectively. We also demonstrated that there were optimal and worst examination strategies, which were determined by the total resources and testing costs. The testing-SEIRD model is useful in making decisions on examination strategies for the emerging infectious disease outbreaks. 


\section{Introduction}

Coronavirus disease 2019 (COVID-19) emerged in Wuhan, China. It has already spread worldwide [1,2]. So far, 5.5 million people have been infected, and 350,000 people have died [3]. Owing to its high transmission ability via aerosol, COVID-19 is an emerging concern in global health care. This is similar to influenza, which annually leads to 300,000 to 600,000 deaths worldwide [4]. In addition, the fatality rate of COVID-19 is $3 \%-4 \%$, which is relatively higher than $1 \%$ for influenza [5], owing to lack of a specific radical treatment or vaccine. Even worse, the infectious period of COVID-19 is 20 days longer than the three days for influenza [6], and COVID-19 causes multiple secondary infections. Therefore, testing for COVID-19 is important for the early detection of asymptomatic infected people and prevention of secondary infections. However, the effect of testing policy on the spread or reduction of COVID-19 infection dynamics remains elusive.

Currently, there is a social problem because medical resources in hospitals are largely consumed by treatments for COVID-19 patients. Symptomatic treatments for patients with pneumonia require both beds haemodialysis, and extracorporeal membrane oxygenators. If symptoms develop, intensive care units are necessary. Consequently, hospital stay for COVID-19 has become exceedingly long, indicating a median of 29 days [7-11]. The imbalance between the supply and demand of medical resources causes the increase in the number of deaths after infection [11,12]. Therefore, each country must control the balance between the medical supply and demand from people who visit hospitals and need testing for COVID-19.

There is a controversy between two extreme policies to balance the medical supply and demand: "mass testing policy" and "no testing policy" [13]. The mass testing policy claims that all people must be tested for public health, regardless of the symptoms. As the director of WHO, Tedros said, "test, test, test" in an opening remark on 16 March 2020 [14]. The WHO and some researchers follow the mass testing policy $[15,16]$. This policy is based on the assumption that the testing accuracy is sufficiently high, and when more testing is conducted, the total number of deaths is reduced. Contrary to the mass testing policy, no testing policy claims that testing must be limited to people with symptoms. This indicates that it does not recommend testing for people with asymptomatic or mild symptoms or having no contact with infectious people. This policy underlies the idea that individuals are unable to expect a benefit from mass testing in the absence of the specific treatment. This was expressed by the committee for the emerging and re-emerging infectious disease in the Japanese society of paediatrics on 13th March 2020 [17]. Although there is discordance in these two policies with different beliefs, these two policies agree with testing on people with symptoms. They also disagree on the extent of the population tested.

Essentially, society demands the minimisation of the number of deaths [18]. Thus, we need to explore the most practical policy by integrating these extreme policies. Consequently, we must notice the advantages and disadvantages of testing. The proof of testing is simply that it can detect infected asymptomatic people. Thus, testing is helpful to save lives before developing severe symptoms and can prevent further spread of the infection. The reason for testing is that testing itself is not perfect, and it is 
inevitable from false positives and negatives. If uninfected people are evaluated as positive by testing (i.e., false positives are hospitalised), the people are subject to the risk of high infection from infected patients in the hospital.

The examination has two strategies: follow-up testing-dominant strategies which follow the exposed population and mass testing-dominant strategy which considers the infected population by random testing. However, the extent to which the follow-up and mass testing should be conducted to minimise deaths, hospitalisations, and positive tests is yet to be considered. Therefore, we need to predict the infection dynamics affected by the examination strategies, or the rate of follow-up and mass testing. We also noticed that the effect of testing on the overall infection population dynamics has not been adequately considered. Therefore, we need to predict the infection dynamics affected by the amount of testing by considering the testing characteristics (i.e., sensitivity and specificity) to quantify their positive and negative impacts.

In this study, we develop a testing-SEIRD model by introducing a hospitalised subpopulation, examination strategy, and testing characteristics. Through simulations, we examined the impact of the examination strategies and testing characteristics on the balance between medical supply and demand. We based on the testing characteristics. 


\section{Model}

To examine the effect of testing on the infection population dynamics, we developed a new model by introducing a hospitalised subpopulation, examination strategy, and testing characteristics into the classical SEIRD model. In general, the SEIRD model is described by the subpopulation dynamics of susceptible, exposed, infectious, recovered, and dead people (Fig. 1A) as:

$$
\begin{gathered}
\frac{d S}{d t}=-\frac{b I S}{N}, \#(2.1) \\
\frac{d E}{d t}=\frac{b I S}{N}-g E, \#(2.2) \\
\frac{d I}{d t}=g E-(r+d) I, \#(2.3) \\
\frac{d R}{d t}=r I, \#(2.4) \\
\frac{d D}{d t}=d I, \#(2.5),
\end{gathered}
$$

where $S, E, I, R$, and $D$ indicate the populations of susceptible, exposed, infectious, recovered, and dead people, respectively. $N$ indicates the total population, that is, $N=S+E+I+R . \quad b$ indicates the exposure rate, which reflects the level of social activity; $g, r$, and $d$ indicate the transition rates among the subpopulations. For this model, it is assumed that the recovered populations acquire permanent immunity, indicating that they will never be infected.

Regarding the testing-SEIRD model, we incorporated the testing characteristics and examination strategy into the classical SEIRD model by dividing the population into outside and inside of the hospitals (Fig. 1B). The dynamics of the population outside the hospitals are described by:

$$
\begin{gathered}
\frac{d S_{o}}{d t}=-\frac{b I_{o} S_{o}}{N_{o}}+u E_{o}-a S_{h}, \#(2.6) \\
\frac{d E_{o}}{d t}=-\frac{b I_{o} S_{o}}{N_{o}}-(u+g) E_{o}-f(1-S p) E_{o} H\left(C-N_{h}\right), \#(2.7) \\
\frac{d I_{o}}{d t}=g E_{o}-\left(r_{o}+d_{o}\right) I_{o}-m S e I_{o} H\left(C-N_{h}\right), \#(2.8) \\
\frac{d R_{o}}{d t}=r_{o} I_{o}, \#(2.9) \\
\frac{d D_{o}}{d t}=d_{o} I_{o}, \#(2.10)
\end{gathered}
$$

and those inside hospitals were described by:

$$
\frac{d S_{h}}{d t}=-\frac{b I_{h} S_{h}}{N_{h}}+u E_{h}+a S_{h}, \#(2.11)
$$




$$
\begin{gathered}
\frac{d E_{h}}{d t}=\frac{b I_{h} S_{h}}{N_{h}}-(u+g) E_{h}+f(1-S p) E_{o} H\left(C-N_{h}\right), \#(2.12) \\
\frac{d I_{h}}{d t}=g E_{h}-\left(r_{h}+d_{h}\right) I_{h}+m S e I_{o} H\left(C-N_{h}\right), \#(2.13) \\
\frac{d R_{h}}{d t}=r_{h} I_{h}, \#(2.14) \\
\frac{d D_{h}}{d t}=d_{h} I_{h}, \#(2.15) .
\end{gathered}
$$

$118 X_{o}$ and $X_{h}$ indicate each population outside and inside the hospitals $(X \in\{S, E, I, R, D, N\}) . N_{o}$ and $N_{h}$ 119 indicate the total populations outside and inside hospitals, respectively (i.e., $N_{o}=S_{o}+E_{o}+I_{o}+R_{o}+R_{h}$ and $\left.120 N_{h}=S_{h}+E_{h}+I_{h}\right) ; a$ indicates the rate of discharge of $S_{h}$ from hospital to the outside; $u$ and $g$ indicate the non121 infection and infection rates, respectively; and $C$ indicates the capacity of hospitals. We assumed that these 122 parameters are determined by the nature of the disease; thus, they are independent of inside and outside hospitals. $r_{j}$ and $d_{j}(j \in\{o, h\})$ indicate the recovery and death rates from infected, respectively, where $r_{o}<r_{h}$, and $d_{h}<d_{o} . f$ and $m$ indicate the rates of follow-up and mass testing, corresponding to the extent to which health centres follow exposed populations and take-up infected populations having symptoms, respectively. $S p$ and $S e$ indicate specificity and sensitivity, respectively, as testing characteristics. Mass testing in this model is a mass test for individuals who claim symptoms. This model is a generalised version of the classic SEIRD model. If $u=0$, our model is equivalent to the classical SEIRD model. The hospitalisation capacity was introduced by the sigmoid function $H(x)=1 /(1+\exp (x))$. The parameter values and initial conditions are listed in Table 1 and discussed in the Materials and Methods section. 


\section{Results}

We first examine the basic behaviour of the testing-SEIRD model by simulation as shown in Fig. 2. Similar to the classical SEIRD model, infection largely expanded, and the infectious population $\left(I_{h}\right.$ and $\left.I_{o}\right)$ transiently increased in response to the occurrence of infectious people. Susceptible populations $\left(S_{h}\right.$ and $\left.S_{o}\right)$ gradually decreased and shifted into recovered populations $\left(R_{h}\right.$ and $\left.R_{o}\right)$ through the exposed $\left(E_{h}\right.$ and $\left.E_{o}\right)$ and infectious $\left(I_{h}\right.$ and $I_{o}$ ) states. During this process, the number of dead cells increases gradually as shown in Fig. 2A. The hospitalised population increase, plateau at the capacity of hospitalisations within the period of infection overshoot, and decrease by the hospital discharge (Fig. 2B). The outside population decrease by hospitalisations through testing and switch to a constant decrease, whereas the hospitalised population reaches its capacity and increases by the hospital discharge (Fig. 2B). Moreover, the outside and hospitalised populations are divided into five types of populations (susceptible, exposed, infectious, recovered, and dead) (Fig. 2C and D). Daily reports of positive tests and deaths transiently increase with different peak timings, and the peak of positive tests precedes that of deaths (Fig. 2E). Reproduction numbers (see Materials and Methods) outside hospitals $R N_{o}$ switch from greater than one to less than one around the peak timing of infectious populations outside (Fig. 2F). On the contrary, reproduction numbers inside hospitals $R N_{h}$ are less than one. This indicates that the infectious population in hospitals increases owing to supply from the outside; however, it is not because of the infectious spread in hospitals. The testing-SEIRD model recapitulates basic infection dynamics of the total population as observed in the classical SEIRD model (Fig. $2 \mathrm{~A}$ ), and enables us to examine the effect of the examination strategy and testing characteristics with different populations inside and outside hospitals.

To investigate the impact of hospitalisation capacity on infection dynamics, such as daily reports of positive tests, hospitalisations, and deaths, we simulate the testing-SEIRD model with various capacities (Fig. $3 \mathrm{~A}$ to $\mathrm{C})$. We observe that as the capacity increases, the maximum positive tests, maximum hospitalisations, and cumulative deaths linearly decrease, increase, and decrease, respectively, and they all plateau at approximately $30 \%$ capacity (Fig. 3D to F). We have also examined their peak timings and have observe that they change nonlinearly, with certain time window ranges (Fig. 3G-I). These results suggest that the change in capacity has a large effect on the level of spread of the disease; nonetheless, it has a small effect on timing.

To illustrate the impact of the examination strategy on infectious outcomes, we examined the cumulative deaths, maximum number of positive tests and hospitalisations, varying follow-up and mass testing rates. The infectious spread shows an all-or-none response depending on the testing strategy (red and blue regions in Fig. 4). Sensitivity analyses confirmed that such a profile was robustly maintained independent of the model parameters (Fig. S1 and S2).

The number of cumulative deaths is almost constant with a small amount of both the follow-up and mass testing (red region in upper panel of Fig. 4A); nonetheless, the combination of follow-up and mass testing cooperatively suppresses the infectious spread (blue region in the upper panel of Fig. 4A). We also realize that the maximum number of hospitalisations is immediately saturated by either the follow-up or mass testing because of the limited hospitalisation capacity (upper panel in Fig. 4B). The maximum number 
of positive tests increases more efficiently with the follow-up testing rate compared to the mass testing rate (upper panel in Fig. 4C).

Subsequently, realistic scenarios were considered by adapting the limited resource $L$. Practically, we cannot freely control the follow-up and mass testing rates because of the limited clinical resources for both the follow-up and mass testing. Thus, it is necessary to determine the amount of resources allocated to the follow-up and mass testing. Here, we consider all the possible decisions subject to the limited resource $L$ as:

$$
L=c_{f} f+c_{m} m, \#(3.1),
$$

where $c_{f}$ and $c_{m}$ indicate the costs for follow-up and mass testing, respectively; $f$ and $m$ are reflected by the decisions on how much follow-up and mass testing are conducted. Considering different $L, c_{f}$, and $c_{m}$, based on the disease, economic and technological situations of each country, we depicted three lines. We observe that the worst decisions (i.e., the choice of $f$ and $m$ ) drastically varied depending on the situation (lower panels of Fig. 4).

Regarding the high resource and low ratio of the cost of follow-up testing to that of the mass testing cost, the number of cumulative deaths abruptly increases more than $90 \%$ compared to the resource fraction assigned to mass testing (green line in Fig. 4A). This indicates that the mass testing dominant testing is the worst strategy for minimising the cumulative deaths. On the contrary, considering low resource and high ratio of follow-up cost to mass testing cost, the number of cumulative deaths abruptly decreases at the resource fraction of $20 \%$ to $30 \%$ (blue line in Fig. 4A) assigned to mass testing. Contrary to the previous case, this result suggests that follow-up-dominant testing is the worst strategy. Regarding the intermediate situation between the two cases above, the simulation showed a U-shape with the resource fraction assigned to mass testing ranging from approximately 10 to $80 \%$ (orange line in Fig. 4A). This indicates that both follow-up and mass-dominant testing are strategies to avoid, whereas the optimal strategy is a combination of the follow-up and mass testing. The choice of $f$ and $m$ also changed in the profiles of maximum hospitalisations and positive reports (Fig. 4B and C). Taken together, the optimal strategy for each country/region should be sought with the resources considered.

Moreover, we examined how the three variables (i.e., the number of cumulative deaths, hospitalisations, and positive tests) are affected by the testing characteristics (i.e., sensitivity and specificity). We conducted sensitivity analyses for $S e$ and $S p$ with values from zero to four with 0.01 increments. We obtained almost the same heatmaps in the sensitivity-specificity space although the heatmaps were inverted along the x-axis (Fig. 5). The equations (2.7, 2.8, 2.12, and 2.13) reveal that sensitivity and one-specificity essentially play the same roles in the follow-up and mass testing. The sensitivity and specificity of the test are not modifiable, whereas the testing strategy can be arbitrary. If the sensitivity is low, an increase in the mass testing rate can lead to the same infectious result with high sensitivity. On the contrary, if the specificity is low, a decrease in the follow-up testing rate can lead to the same infectious result with high specificity. Therefore, we must manage the optimal testing strategy based on the unmodifiable testing sensitivity and specificity.

We have investigated how the infection is expanded based on the testing strategy. However, this is the point of view of a perfect observer who knows the exact time course of the latent populations. Practically, 
206 we are unable to know all the model variables, such as exposed and infectious populations inside and outside 207 hospitals; nonetheless, we can merely monitor positive reports by follow-up and mass testing. In this study, 208 we verify whether these two kinds of positive reports reflect the latent infectious population, which is the 209 most resource-consuming and challenging social issue. Using regression analysis (see Materials and 210 Methods), we demonstrate that latent infectious populations can be predicted from daily positive reports of 211 follow-up and mass testing (Fig. 6A to C). These results suggest that the infectious population is not simply 212 proportional to the sum of positive reports of follow-up and mass testing; nevertheless, they are proportional 213 to their weighted sum (Fig. 6D). There are cases in which either weights can be negative, depending on the 214 model parameters. We found that the weight for positive reports of follow-up testing was negative with high 215 positive predictive values. This is because the negative weight of $P_{f}$ acts in a repressive manner to estimate 216 the latent number of infectious people, reflecting a low positive predictive value (Fig. 6D). 


\section{Discussion}

We develop a testing-SEIRD model to consider two discrete populations inside and outside hospitals, impact of examination strategy (follow-up testing $[f]$, and mass testing $[m]$ ), and testing characteristics (sensitivity $[S e]$ and specificity $[S p]$ ) on three variables (i.e., the number of maximum positive tests, maximum hospitalisations, and cumulative deaths (Fig. 1)). We also demonstrate that the optimal and worst examination strategies are subject to limited testing resources (Fig. 4). In addition, we highlight the possibility that the infectious population can be predicted by a weighted sum of positive reports from followup and mass testing (Fig. 6).

\section{(a) Comparison with previous models.}

There are several models of infectious dynamics, such as SIR [19], SEIRD models, and their alternatives, which have been widely used for policy making through model simulation $[1,4,20-26]$. However, some of the previous models do not include the hospital compartment, [20,25,27-29] and other models, even with hospital compartments, do not consider the examination strategy and testing characteristics [22,30]. They cannot address how the examination strategy and testing characteristics affect infectious population dynamics, such as clinical and social overshoot. Consequently, we develop the testing-SEIRD model by introducing new factors: the hospital compartment, examination strategy, and testing characteristics to the previous SEIRD model (Fig. 2 and 3). The testing-SEIRD model generalises the classical SEIRD model, and it can be equivalent to the classical SEIRD model if the examination strategy is removed $(f=0, m=0)$.

(b) Model prediction

This model has three advantages. First, the testing-SEIRD model provides the best examination strategy for situations. The model provided heatmaps of the number of the three variables in the space of the examination strategy (Fig. 4). This map indicates the best direction as shown in the blue region in Fig. 4. This corresponds to the settling of infections using the shortest path. Second, the testing-SEIRD model can predict the optimal and worst strategies, considering the limited resources and ratios for the testing costs (Fig. 4). Because the total resource and testing costs depend on countries, our model offers the best examination strategy unique to each country. Third, the testing-SEIRD model demonstrate that the latent number of infectious population

\section{(c) Validity of model components}

Here, we discuss the validity of the model components, which previous models do not have. First, we focus on the transition from $E_{o}$ to $E_{h}$ (Fig. 1). We assume that the hospitalisation of the exposed population is induced by the follow-up testing. Populations that are just exposed before developing symptoms do not take the tests themselves. They test only when urged by the follow-up. Second, related to the transition from $\mathrm{I}_{\mathrm{o}}$ to $\mathrm{I}_{\mathrm{h}}$, we assume that the hospitalisation of the infectious population is induced by the mass testing, which is 
modifiable parameter because the rate depends on the volume of the tests, such as polymerase chain reaction (PCR) and the degree of social penalty if it is positive. Third, we consider the transition from $E_{o}$ to $S_{o}$ and $E_{h}$ to $S_{\mathrm{h}}$. Regarding our model, all the exposed populations are not necessarily infected and some return susceptible compared to the previous models which assume that all the exposed populations are destined to be infected [20,22,24,25,27-33]. Consistent with our model, it is well known that some exposed populations return to susceptible populations without developing symptoms.

\section{(d) Future studies}

263 Considering the future perspectives of our model, first, our testing-SEIRD model simulates only a single peak time course of infection. However, we observed multiple peaks of COVID-19 infection in many countries [34]. To incorporate the multiple peaked dynamics, we must introduce the socio-psychological effects caused by policies such as lockdown and social distancing. Second, our model assumes that all the populations are homogeneous and do not address stratification based on attributes such as gender, age, social activities, and comorbidities [35,36]. A future study should consider this perspective. Finally, our model does not include the effects of vaccination. We are currently fighting the spread of COVID-19 using messenger RNA (mRNA) vaccines. It seems we are getting successful results; however, we do not know the duration of the effect of the vaccinations and its robustness against mutants $[34,37,38]$. Therefore, the tag-of-war model between vaccines and virus evolution remains elusive. 


\section{5.Materials and Methods}

(a) Parameter set

The parameters and initial conditions of the simulation are listed in Table 1A. The total population $N$ was set to 1,000,000 according to the United Nations Statistical Papers: The World's Cities in 2018, which mentioned that one in five people worldwide lives in a city with more than one million inhabitants and the median value of inhabitants is between 500,000 and one million [39]. Sensitivity $S e$ and specificity $S p$ were both set to 0.7, which correspond to those of the PCR for detecting COVID-19 (Table 1B) [20,31,40-42]. The values of $b, g, r_{h}, r_{o}$, and $d_{h}$ are based on previous reports (Table 1C) [3,21-26,28-30,32]. The sum of $u$ and $g$ is the inverse of the incubation period during the exposed state, which is reported to be five days (Table 1C) [23-25,33,41,43,44]. The sum of $r$ and $d$ is the inverse of the infectious period during the infectious state, which is reported to be ten days (Table 1D) [23,24,27,41,43].

\section{(b) Definitions of reproduction numbers}

Considering Fig. 2, we computed the time courses of reproduction numbers inside and outside hospitals: $R N_{h}$ and $R N_{o}$.

$$
\begin{gathered}
R N_{h}=\frac{1}{r_{h}+d_{h}} \cdot \frac{b S_{h}}{S_{h}+E_{h}+I_{h}} \cdot \frac{g}{u+g}, \#(5.1) \\
R N_{o}=\frac{1}{r_{o}+d_{o}} \cdot \frac{b S_{o}}{S_{o}+E_{o}+I_{o}+R_{o}+R_{h}} \cdot \frac{g}{u+g} . \#(5.2)
\end{gathered}
$$

Here, the first, second, and third factors in these equations indicate the average infectious period, infection rate, and probability that the exposed state transits to the infectious state, respectively. The reproduction number in the classical SEIRD model is defined in previous studies [1,4,20-26] as:

$$
R N=\frac{1}{r+d} \cdot \frac{b S}{S+E+I+R} . \#(5.3)
$$




\section{Acknowledgments}

295 We thank Tomohiko Takada M.D. (Ph.D.) and Yoshika Onishi M.D. (Ph.D.) for providing the basic concept of 296 clinical NNT. We also thank Prof. Hiroshi Nishiura for providing the fundamental knowledge of infectious disease modelling by organising a summer boot camp in 2014.

\section{Funding}

This study was partly supported by the Cooperative Study Program of Exploratory Research Centre on Life and Living Systems (ExCELLS) (program Nos.18-201, 19-102, and 19-202 to H.N.), a Grant-in-Aid for Young Scientists (B) (16K16147 and 19H04776 to H.N.) from the Japan Society for the Promotion of Science (JSPS).

\section{Ethics}

Any human or animal subjects are not involved in this manuscript.

\section{Data Availability}

All relevant data are within the study and its supporting information files.

Code Availability

https://github. com/bougtoir/testing-SEIRD

O.T. and Y.I. conceived of the initial ideas. O.T. developed and implemented the method, processed, and analysed the data, and wrote the initial draft of the manuscript. H.N. edited the initial draft of the manuscript and reviewed the method. Y.I. supervised the project. All authors contributed to the final writing of the manuscript.

\section{Competing Interests}

The authors declare no competing interests. 


\section{References}

322 1. Shereen MA, Khan S, Kazmi A, Bashir N, Siddique R. 2020 COVID-19 infection: Origin, transmission, and characteristics of human coronaviruses. Journal of Advanced Research 24, 91-98. (doi:10.1016/j.jare.2020.03.005) Clinical Aspects of COVID-19; a Nar- rative Review. Clinical Aspects of COVID 8, 41.

3. Johns Hopkins Coronavirus Resource Center. In press. COVID-19 Map - Johns Hopkins Coronavirus Resource Center. See https://coronavirus.jhu.edu/map.html (accessed on 21 May 2020). Roguski KM et al. 2019 Estimates of global seasonal influenza-associated respiratory mortality: a modelling study. The Lancet 391, 1285-1300. (doi:10.1016/S0140-6736(17)33293-2.Estimates) World health organization. In press. Coronavirus disease 2019 (COVID-19) Situation Report - 46.

6. Zhou F et al. 2020 Clinical course and risk factors for mortality of adult inpatients with COVID-19 in Wuhan, China: a retrospective cohort study. The Lancet 395, 1054-1062. (doi:10.1016/S0140-6736(20)30566-3)

7. Giwa AL, Desai A, Duca A. 2020 Novel 2019 coronavirus SARS-CoV-2 (COVID-19): An updated overview for emergency clinicians. Emergency medicine practice 22, 1-28.

8. Zhu S, Guo X, Geary K, Zhang D. 2020 Emerging Therapeutic Strategies for COVID-19 Patients. Discoveries 8, e105. (doi:10.15190/d.2020.2)

9. Stratton SJ. 2020 COVID-19: Not a Simple Public Health Emergency. Prehospital and Disaster Medicine 35, 119. (doi:10.1017/S1049023X2000031X)

10. Swiss Academy Of Medical Sciences. 2020 COVID-19 pandemic: triage for intensive-care treatment under resource scarcity. Swiss medical weekly 150, w20229. (doi:10.4414/smw.2020.20229)

11. The Japanese society of intensive care medicine. In press. COVID19 Clinical report 20200322 v3. ANZICS. In press. ANZICS COVID-19 Guidelines Version 2 - ANZICS. See https://www.anzics.com.au/anzics-covid-19guidelines-version-2/ (accessed on 21 May 2020).

13. Our world in Data. In press. GitHub - owid/covid-19-data: Data on COVID-19 (coronavirus) cases, deaths, hospitalizations, tests • All countries • Updated daily by Our World in Data. See https://github.com/owid/covid-19-data (accessed on 21 May 2020).

14. World health organization. In press. WHO Director-General's opening remarks at the media briefing on COVID-19 - 16 March 2020. See https://www.who.int/director-general/speeches/detail/who-director-general-s-opening-remarks-at-themedia-briefing-on-covid-19---16-march-2020 (accessed on 21 May 2020).

16. Peto J. 2020 Covid-19 mass testing facilities could end the epidemic rapidly. The BMJ 368, 110110. (doi:10.1136/bmj.m1163)

17. Japanese society of pediatrics. In press. Thought on COVID-19 testing. See http://www.jpeds.or.jp/modules/activity/index.php?content_id=329 (accessed on 21 May 2020).

18. Joebges S, Biller-Andorno N. 2020 Ethics guidelines on COVID-19 triage - An emerging international consensus. Critical

Care 24, 1-5. (doi:10.1186/s13054-020-02927-1)

19. Phelan. 2018 Mathematical models to characterize early epidemic growth: A Review Gerardo. Physiology \& behavior 176, 
139-148. (doi:10.1016/j.plrev.2016.07.005.Mathematical)

Fang Y, Nie Y, Penny M. 2020 Transmission dynamics of the COVID-19 outbreak and effectiveness of government interventions: A data-driven analysis. Journal of medical virology (doi:10.1002/jmv.25750)

21. Tang B, Bragazzi NL, Li Q, Tang S, Xiao Y, Wu J. 2020 An updated estimation of the risk of transmission of the novel coronavirus (2019-nCov). Infectious Disease Modelling 5, 248-255. (doi:10.1016/j.idm.2020.02.001)

22. Kucharski AJ et al. 2020 Early dynamics of transmission and control of COVID-19: a mathematical modelling study. The Lancet Infectious Diseases 20, 553-558. (doi:10.1016/S1473-3099(20)30144-4)

23. Backer J, Klinkenberg D, Wallinga J. 2020 The incubation period of 2019-nCoV infections among travellers from Wuhan, China. Eurosurveillance , 1-6. (doi:10.1101/2020.01.27.20018986)

Bi Q et al. 2020 Epidemiology and transmission of COVID-19 in 391 cases and 1286 of their close contacts in Shenzhen, China: a retrospective cohort study. The Lancet Infectious Diseases 20, 911-919. (doi:10.1016/S1473-3099(20)30287-5) Kuniya T. 2020 Prediction of the Epidemic Peak of Coronavirus Disease in Japan, 2020. Journal of clinical medicine 9. (doi:10.3390/jcm9030789) Linton NM, Kobayashi T, Yang Y, Hayashi K, Akhmetzhanov AR, Jung SM, Yuan B, Kinoshita R, Nishiura H. 2020 Incubation period and other epidemiological characteristics of 2019 novel coronavirus infections with right truncation: A statistical analysis of publicly available case data. Journal of Clinical Medicine 9, 538. (doi:10.1101/2020.01.26.20018754)

27. Joseph TW, Leung K, Leung GM. 2020 Nowcasting and forecasting the potential domestic and international spread of the 2019-nCoV outbreak originating in Wuhan, China: a modelling study. The Lancet, 689-697.

28. Iwata K, Miyakoshi C. 2020 A Simulation on Potential Secondary Spread of Novel Coronavirus in an Exported Country Using a Stochastic Epidemic SEIR Model. Journal of Clinical Medicine 9, 944. (doi:10.3390/jcm9040944)

29. Sun H, Qiu Y, Yan H, Huang Y, Zhu Y, Gu J, Chen S. 2021 Tracking Reproductivity of COVID-19 Epidemic in China with Varying Coefficient SIR Model. Journal of Data Science 18, 455-472. (doi:10.6339/jds.202007_18(3).0010)

31. Lin L et al. 2020 Artificial Intelligence Distinguishes COVID-19 from Community Acquired Pneumonia on Chest CT. Applied Intelligence 2019, 1-5.

32. Roda WC, Varughese MB, Han D, Li MY. 2020 Why is it difficult to accurately predict the COVID-19 epidemic? Infectious Disease Modelling 5, 271-281. (doi:10.1016/j.idm.2020.03.001)

33. World health organization. In press. Report of the WHO-China Joint Mission on Coronavirus Disease 2019 (COVID-19). (accessed on 21 May 2020). Obesity 28, 1375-1377. (doi:10.1002/oby.22881)

6. Shahid Z et al. 2020 COVID-19 and Older Adults: What We Know. Journal of the American Geriatrics Society 68, 926-929. (doi:10.1111/jgs.16472)

Sharp TM et al. 2021 Antibody Persistence through 6 Months after the Second Dose of mRNA-1273 Vaccine for Covid-19. 
medRxiv preprint doi: https://doi.org/10.1101/2021.08.31.21262868; this version posted September 5, 2021. The copyright holder for this preprint

(which was not certified by peer review) is the author/funder, who has granted medRxiv a license to display the preprint in perpetuity.

It is made available under a CC-BY-NC-ND 4.0 International license .

New England Journal of Medicine 384, 2257-2259. (doi:10.1056/nejmc2023298)

38. Christian HH, Daniela M, Sophie MG, Kåre M, Steen E. 2020 Assessment of protection against reinfection with SARSCoV-2 among 4 million PCR-tested individuals in Denmark in 2020: a population-level observational study. The Lancet , $19-21$.

39. United Nations. 2018 The World's Cities in 2018: Data Booklet. (doi:10.18356/C93F4DC6-EN)

40. Tao A, Zhenlu Y, Hongyan H, Chenao Z, Chong C, Wenzhi L, Qian T, Ziyong S, Liming X. 2014 Correlation of Chest CT and RT-PCR Testing in Coronavirus Disease 2019 (COVID-19) in China: A Report of 1014 Cases. Radiology 80, 1-8. (doi:10.14358/PERS.80.2.000)

41. Long C et al. 2020 Diagnosis of the Coronavirus disease (COVID-19): rRT-PCR or CT? European Journal of Radiology

42. Lai S et al. 2021 Effect of non-pharmaceutical interventions to contain COVID-19 in China. Natutre 585, $410-413$. (doi:10.1038/s41586-020-2293-x.Effect)

43. Fang J, Lau CKM, Lu Z, Wu W, Zhu L. 2019 Natural disasters, climate change, and their impact on inclusive wealth in G20 countries. Environmental Science and Pollution Research 26, 1455-1463. (doi:10.1007/s11356-018-3634-2)44. Ahmad N, Derrible S, Managi S. 2018 A network-based frequency analysis of Inclusive Wealth to track sustainable development in world countries. Journal of Environmental Management 218, 348-354. (doi:10.1016/j.jenvman.2018.04.070) 


\section{A: SEIRD model}

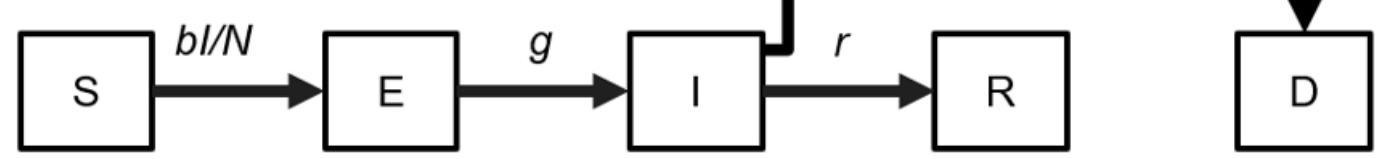

B: Our model

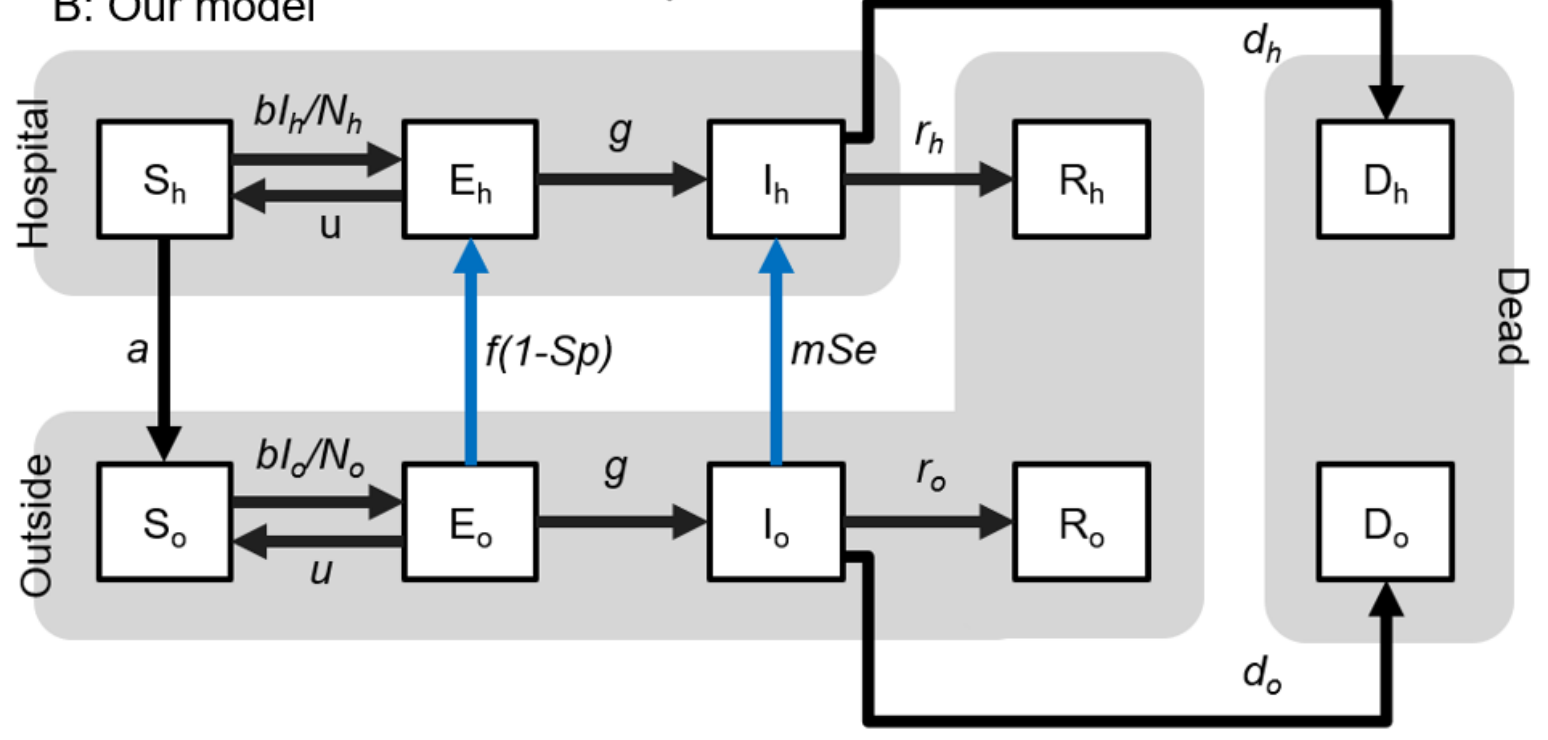

Figure 1: Classical SEIRD and testing-SEIRD models

(A) Classical SEIRD model: Susceptible population ' $S$ ' is exposed by infectious population 'l' at a rate proportional to the fraction of the infectious population. The exposed population ' $E$ ' become infectious 'l'. The infected population finally recovers ' $R$ ' or become dead ' $D$ '. (B) Testing-SEIRD model: The population is divided into two subpopulations; inside and outside hospitals. The exposed ' $E_{0}$ ' and infectious population outside ' $\mathrm{l}_{\mathrm{o}}$ ' are hospitalised if evaluated as positive by testing. Susceptible population ' $\mathrm{S}_{h}$ ' is left from the hospitals. The black lines indicate the transitions of populations, regardless of capacity effect. The blue lines indicate the transitions of the populations, considering the capacity effect. Transitions from both ' $\mathrm{E}_{\mathrm{o}}$ ' to ' $\mathrm{E}_{\mathrm{h}}$ ' and ' $l_{0}$ ' to ' $\mathrm{h}$ ' are determined as hospitalised. 
A: Total population

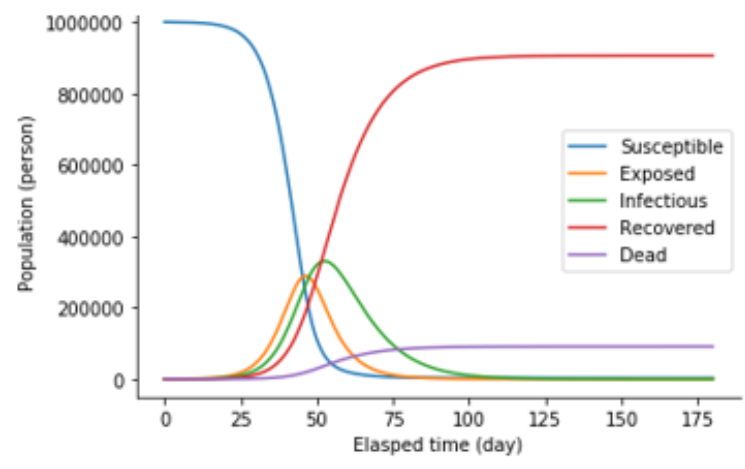

C: Inside hospital

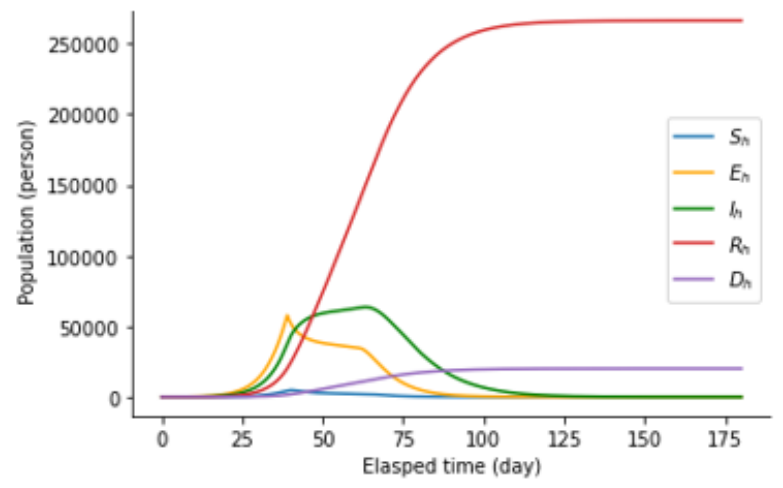

E: Daily reports

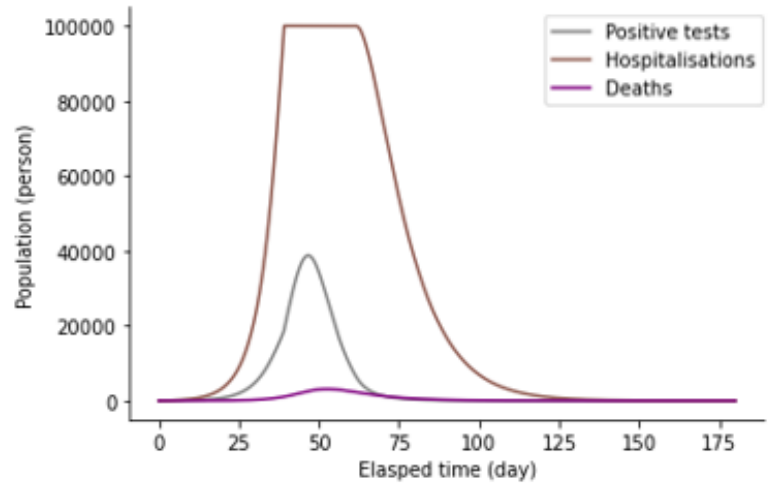

B: Inside and outside hospital and dead

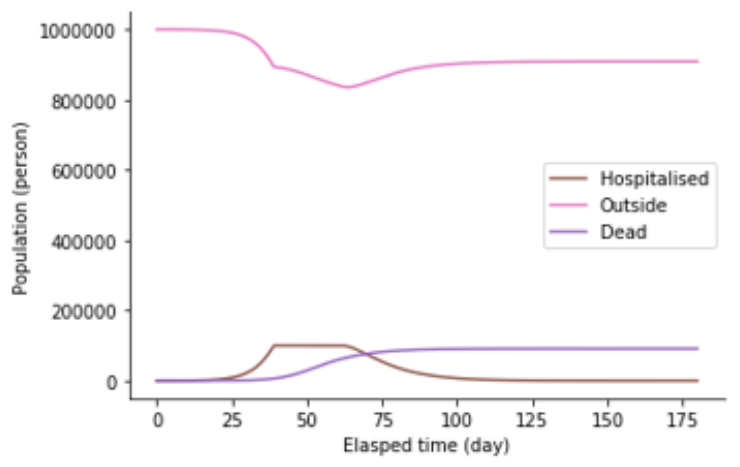

D: Outside hospital

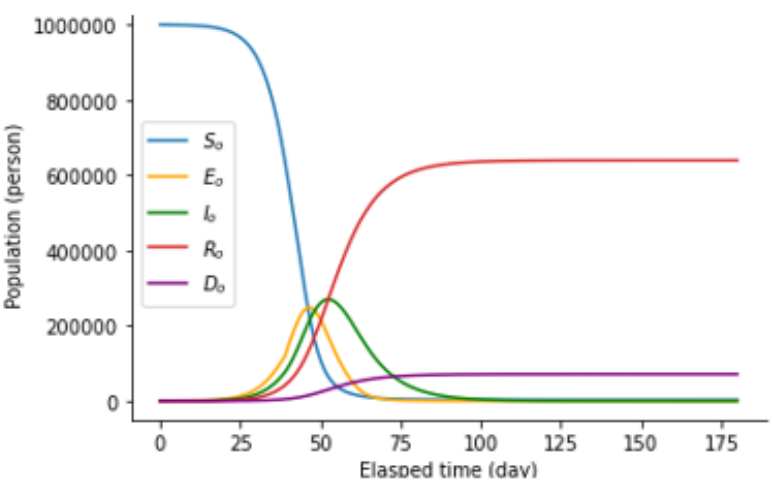

F: Time dependent reproduction number

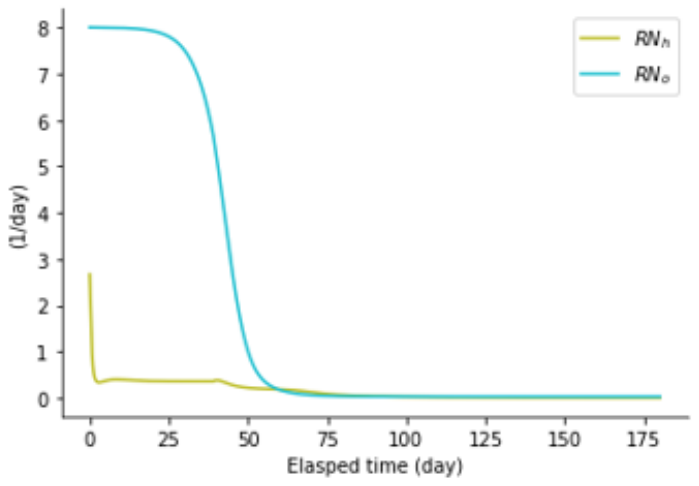

Figure 2: Changes in components over time in the testing-SEIRD model

Time-courses of (A) populations of all infectious states, irrespective of being inside and outside hospitals; (B) Populations inside and outside hospitals and dead populations, irrespective of infectious states; (C) Populations of all infectious states inside hospitals; (D) Populations of all infectious states outside hospitals; (E) Daily reports of positive tests, hospitalisations, and deaths; (F) Time-courses of reproduction numbers inside and outside hospitals, as described in Materials and Methods section. 
medRxiv preprint doi: https://doi.org/10.1101/2021.08.31.21262868; this version posted September 5, 2021. The copyright holder for this preprint (which was not certified by peer review) is the author/funder, who has granted medRxiv a license to display the preprint in perpetuity. It is made available under a CC-BY-NC-ND 4.0 International license .

A
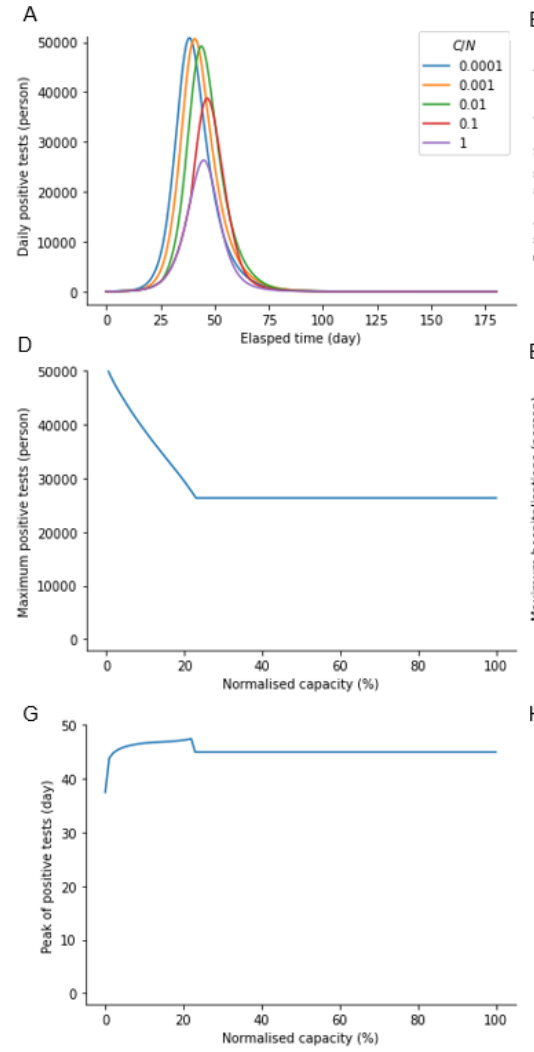

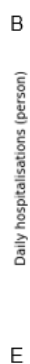
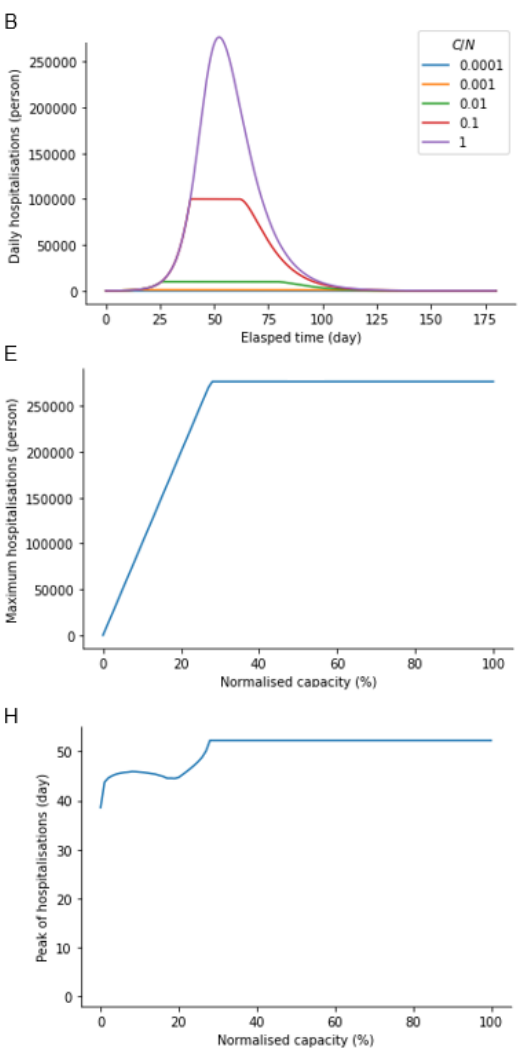
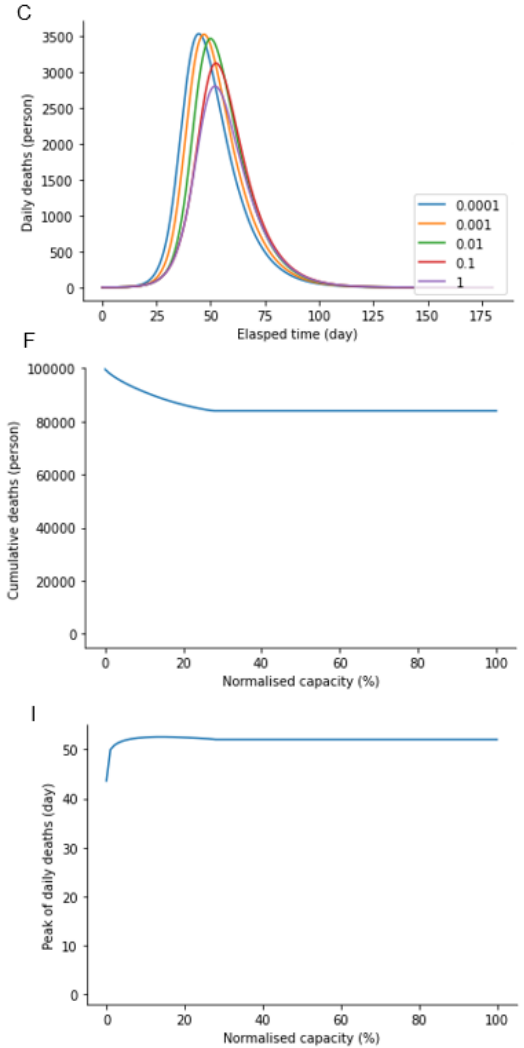

Figure 3: Impact of hospitalisations capacity on the three variables

Time courses of (A) Daily reports of positive tests; (B) Daily reports of hospitalisations; (C) Daily reports of deaths with varying hospitalisation capacity. $\mathrm{C} / \mathrm{N}$ indicates the capacity normalised to the total population. Hospitalisation capacity dependencies of (D) Maximum positive reports; (E) Maximum hospitalisations; (F) Cumulative deaths. Hospitalisation capacity-dependencies of $(G)$ Peaks of daily reports of positive tests; $(H)$ Peaks of hospitalisations; (I) Peaks of daily deaths. 
medRxiv preprint doi: https://doi.org/10.1101/2021.08.31.21262868; this version posted September 5, 2021. The copyright holder for this preprint (which was not certified by peer review) is the author/funder, who has granted medRxiv a license to display the preprint in perpetuity. It is made available under a CC-BY-NC-ND 4.0 International license .

A: Cumulative deaths
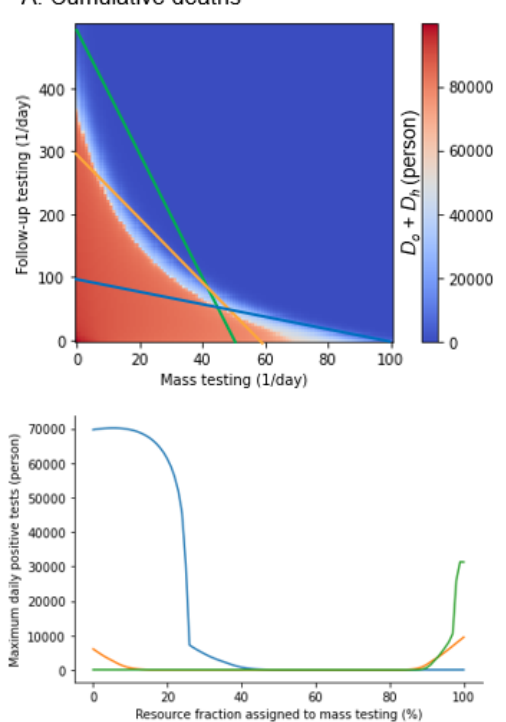

B: Maximum hospitalisations
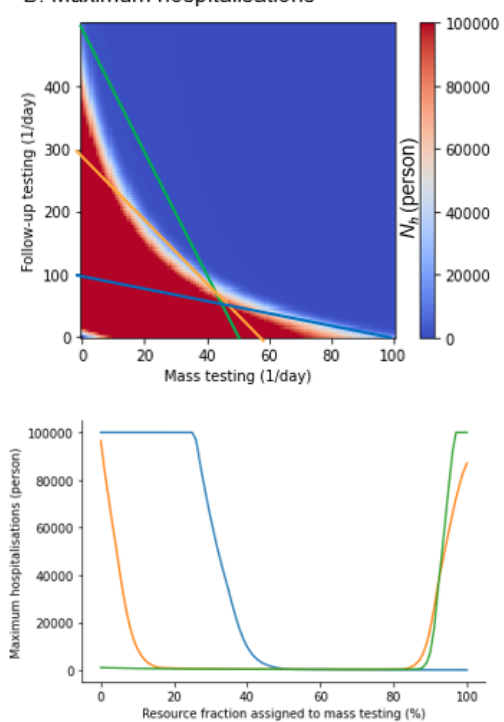

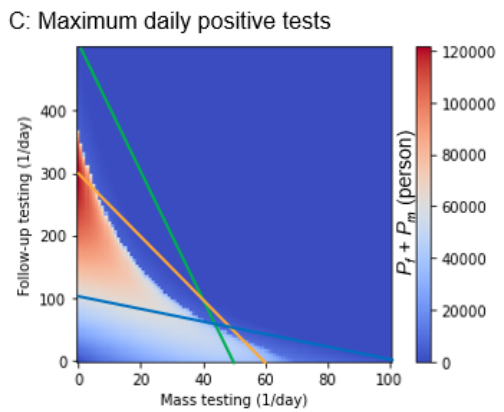

C: Maximum daily positive tests

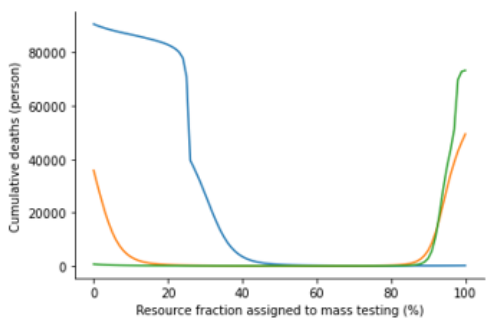

Figure 4: Infectious spread based on the examination strategy

The upper panels represent the number of $(A)$ cumulative deaths,

(B) maximum hospitalisations, and (C) maximum daily positive tests depending on the rates of follow-up and mass testing. The three lines in these heatmaps represent the possible testing strategies subject to different total resources for testing with different ratios for the testing costs. The lower panels represent the numbers along the three lines in the heatmap. 
medRxiv preprint doi: https://doi.org/10.1101/2021.08.31.21262868; this version posted September 5, 2021. The copyright holder for this preprint (which was not certified by peer review) is the author/funder, who has granted medRxiv a license to display the preprint in perpetuity. It is made available under a CC-BY-NC-ND 4.0 International license.

A: Cumulative deaths

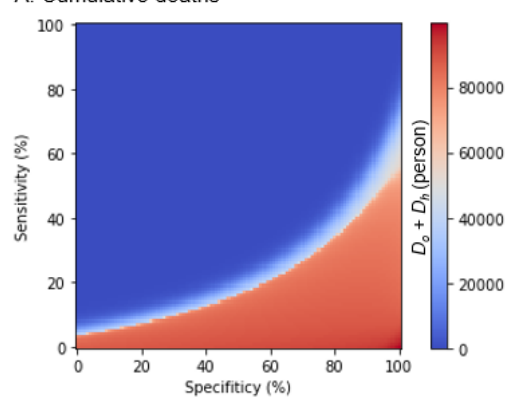

B: Maximum hospitalisations

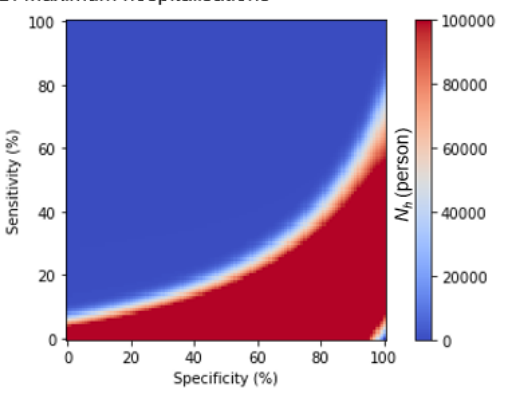

C: Maximum daily positive tests

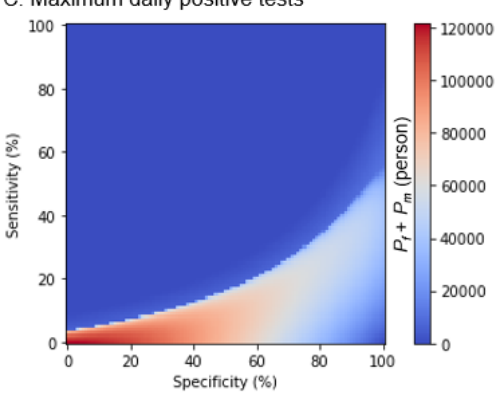

Figure 5: Infectious spread based on the testing properties

Number of (A) Cumulative deaths, (B) Maximum hospitalisations, and (C) Maximum daily positive tests based on the sensitivity and specificity of the testing. 
A: $(f, m)=(0.5,0.01)$

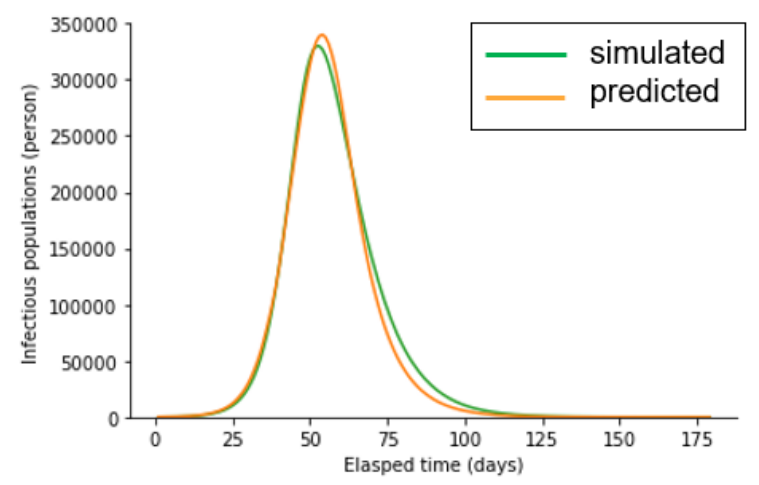

C: $(f, m)=(0.8,0.02)$

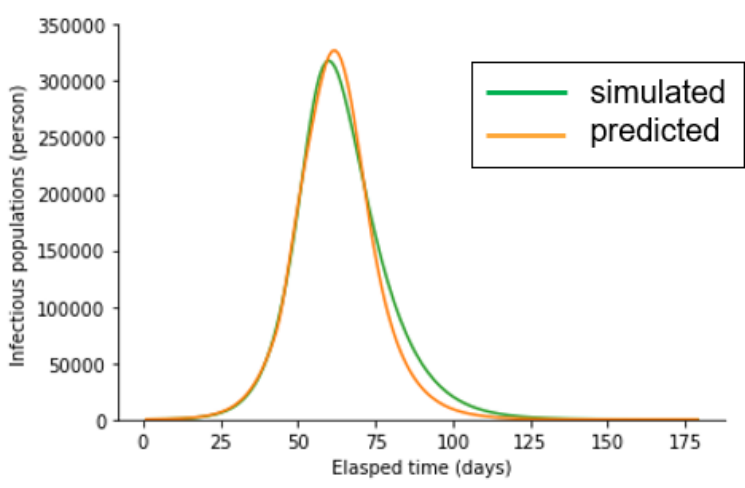

B: $(f, m)=(0.5,0.02)$

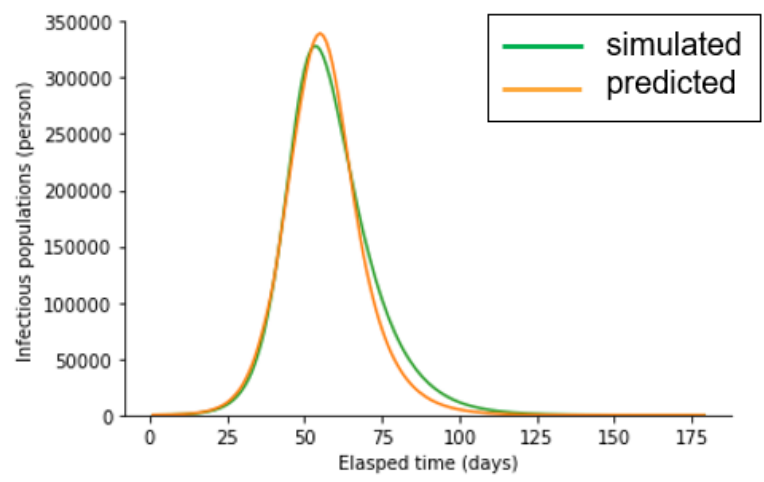

D: Estimated weights for $P f$ and $P m$

$P f / P m$

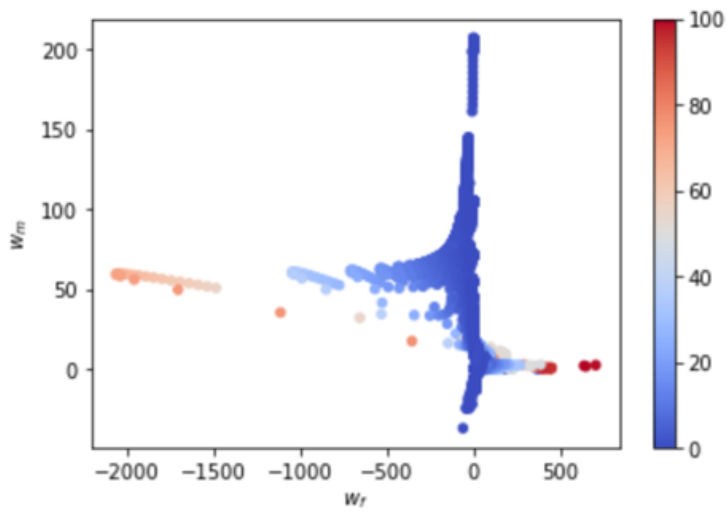

Figure 6: Prediction of infectious population from daily reports of positive tests

(A-C) The Green and orange lines indicate the simulated and predicted infectious populations $\left(I_{h}\right.$ and $\left.I_{0}\right)$ with different examination strategies. The infectious populations are estimated by the linear regression as $w_{f} P_{f}+$ $w_{m} P_{m}$, where $w_{f}$ and $w_{m}$ indicate the weights and $P_{f}$ and $P_{m}$ indicate the daily positive reports of follow-up and mass testing, namely $f(1-S p)$ and $m S e$, respectively. The weights are estimated by the least square method. (D) The estimated weights for $P_{f}$ and $P_{m}$ are plotted, considering various combinations of ratios of the followup cost to the mass testing cost $\left(P_{f} / P_{m}\right)$. 
medRxiv preprint doi: https://doi.org/10.1101/2021.08.31.21262868; this version posted September 5, 2021. The copyright holder for this preprint (which was not certified by peer review) is the author/funder, who has granted medRxiv a license to display the preprint in perpetuity. It is made available under a CC-BY-NC-ND 4.0 International license .

461
C

A

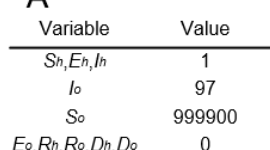

$E_{\circ}, R_{h}, R_{\circ}, D_{h}, D_{\circ} \quad 0$

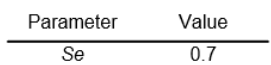

$\begin{array}{ll}\text { Se } & 0.7 \\ \text { Sp } & 0.7\end{array}$

$\begin{array}{cc}S p & 0.05\end{array}$

$\begin{array}{cc}m & 0.01 \\ b & 1\end{array}$

$\begin{array}{ll}b & 1 \\ u & 0.04\end{array}$

$\begin{array}{cc}g & 0.16 \\ r h & 0.093\end{array}$

$\begin{array}{ll}\text { rh } & 0.093 \\ \text { ro } & 0.096\end{array}$

$\begin{array}{ll}d_{h} & 0.007 \\ d_{0} & 0.01\end{array}$

B

\begin{tabular}{ccc} 
Mode of test & Se & $S p$ \\
\hline CT & $0.98^{20}, 0.97^{31,40}$ & 0.828 to $0.96^{41}$ \\
PCR & 0.8 to $0.9^{41}, 0.972^{42}$ & n/a
\end{tabular}

Model

n/a
eSEIR

$\mathrm{n} / \mathrm{a}$

n/a

SEIR

n/a

vSIR

SEIR

SIR/SEIR

0.9 e- 5 to e-6†

$2.1 \mathrm{e}-8$

Fang $^{20}$

Tang $^{21}$

Kucharski ${ }^{22}$

Backer $^{23}$

$\mathrm{Bi} \mathrm{Q}{ }^{24}$

Kuniya ${ }^{25}$

Linton ${ }^{26}$

Iwata ${ }^{28}$

Sun, $\mathrm{H}^{29}$

Rocklöv $^{30}$

Roda $^{32}$ $\mathrm{n} / \mathrm{a}$

$\mathrm{n} / \mathrm{a}$
$\mathrm{n} / \mathrm{a}$

$0.2 \mathrm{e}-8 \dagger$

$\mathrm{n} / \mathrm{a}$

$\mathrm{n} / \mathrm{a}$

n/a

$0.4 \mathrm{e}-4$ or $0.12 \mathrm{e}-4 \dagger$

8.68 e-8 $\frac{g}{0.143}$

$0.143-0.056$

0.126

0.156

0.143 to 0.33

$\mathrm{n} / \mathrm{a}$

$\mathrm{n} / \mathrm{a}$

0.167 to 0.208

n/a

0.2

0.631

D

\begin{tabular}{ccc} 
Reference & Incubation period & Infectious period \\
\hline Kucharski $^{22}$ & 5.2 & 2.9 \\
Backer $^{23}$ & 6.5 & $\mathrm{n} / \mathrm{a}$ \\
$\mathrm{Bi}^{24}$ & 4.8 & 1.5 \\
$\mathrm{Wu}^{27}$ & 6.1 & 2.3 \\
Rocklöv $^{30}$ & 5 & 10 \\
Li $^{31}$ & 5.2 & 2.3
\end{tabular}

WHO-China Joint ${ }^{33}$

\begin{tabular}{cccc}
$r_{n}$ & $r_{o}$ & $d_{h}$ & $d_{o}$ \\
\hline 0.056 & $\mathrm{n} / \mathrm{a}$ & $\mathrm{n} / \mathrm{a}$ & $\mathrm{n} / \mathrm{a}$ \\
$\mathrm{n} / \mathrm{a}$ & 0.14 & $1.78 \mathrm{e}-5$ & $\mathrm{n} / \mathrm{a}$ \\
$\mathrm{n} / \mathrm{a}$ & $\mathrm{n} / \mathrm{a}$ & $\mathrm{n} / \mathrm{a}$ & $\mathrm{n} / \mathrm{a}$ \\
$\mathrm{n} / \mathrm{a}$ & $\mathrm{n} / \mathrm{a}$ & $\mathrm{n} / \mathrm{a}$ & $\mathrm{n} / \mathrm{a}$ \\
$\mathrm{n} / \mathrm{a}$ & $\mathrm{n} / \mathrm{a}$ & $\mathrm{n} / \mathrm{a}$ & $\mathrm{n} / \mathrm{a}$ \\
$\mathrm{n} / \mathrm{a}$ & $\mathrm{n} / \mathrm{a}$ & $\mathrm{n} / \mathrm{a}$ & $\mathrm{n} / \mathrm{a}$ \\
$\mathrm{n} / \mathrm{a}$ & $\mathrm{n} / \mathrm{a}$ & $\mathrm{n} / \mathrm{a}$ & $\mathrm{n} / \mathrm{a}$ \\
0.13 to 0.417 & $\mathrm{n} / \mathrm{a}$ & $\mathrm{n} / \mathrm{a}$ & $\mathrm{n} / \mathrm{a}$ \\
0.1 & $\mathrm{n} / \mathrm{a}$ & $\mathrm{n} / \mathrm{a}$ & $\mathrm{n} / \mathrm{a}$ \\
$\mathrm{n} / \mathrm{a}$ & $\mathrm{n} / \mathrm{a}$ & $\mathrm{n} / \mathrm{a}$ & $\mathrm{n} / \mathrm{a}$ \\
0.1 & $\mathrm{n} / \mathrm{a}$ & $\mathrm{n} / \mathrm{a}$ & $\mathrm{n} / \mathrm{a}$
\end{tabular}

\section{Table 1: Variables and parameters in previous reports}

(A) Initial values for variables and parameters and (B) Reported sensitivity and specificity of PCR and CT for detecting COVID-19. Cells expressed as $\mathrm{n} / \mathrm{a}$ indicate that we cannot find the $(\mathrm{C})$ reported transition parameters with models. Values with $\dagger$ are calculated from the original values for comparison. All the values have dimensions of [one/day]. We cannot find values or models for the cells expressed as $n / a$. The values with $\dagger$ equal original values divided by the total population involved. (D) Reported incubation period and infectious period. All values have dimensions of [day]. 
medRxiv preprint doi: https://doi.org/10.1101/2021.08.31.21262868; this version posted September 5, 2021. The copyright holder for this preprint (which was not certified by peer review) is the author/funder, who has granted medRxiv a license to display the preprint in perpetuity.

It is made available under a CC-BY-NC-ND 4.0 International license .

\section{Supplementary Figures}

$(b, m)=(1,0)$

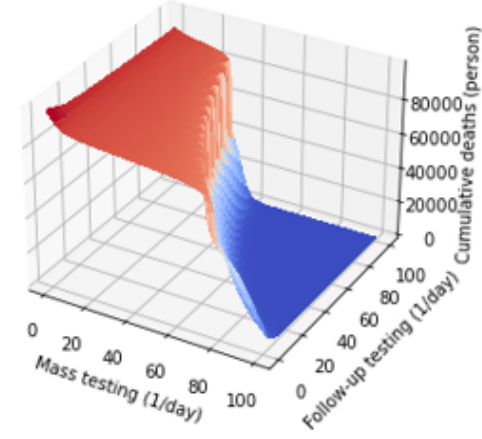

$(b, m)=(1,0.12)$

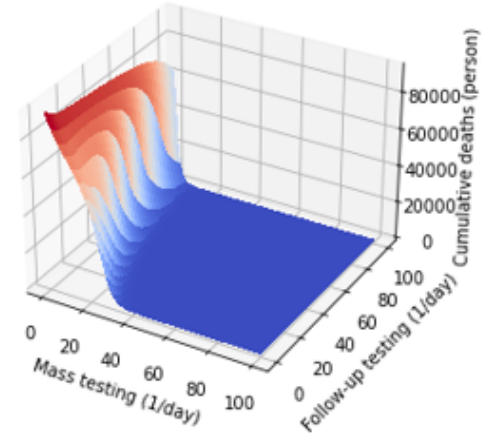

$(b, m)=(0.4,0.04)$

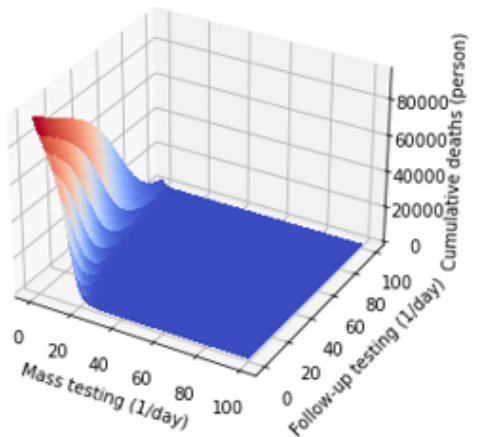

$(b, m)=(1,0.04)$

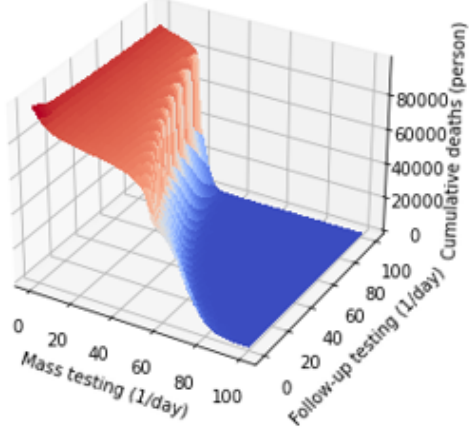

$(b, m)=(1,0.16)$

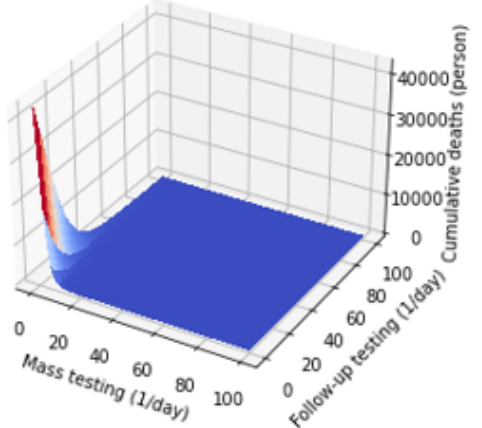

$(b, m)=(0.6,0.04)$

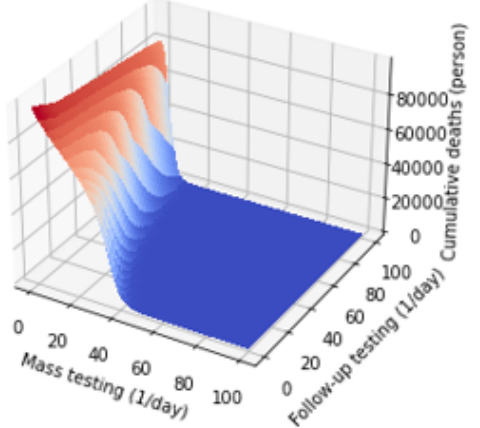

$(b, m)=(1,0.08)$

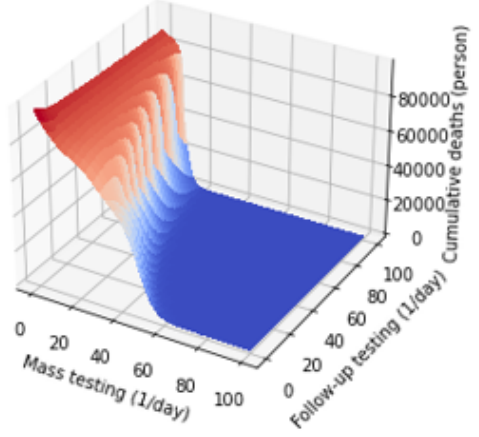

$(b, m)=(0.2,0.04)$

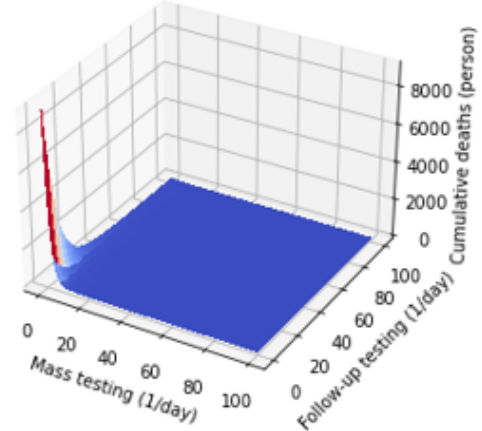

$(b, m)=(0.8,0.04)$

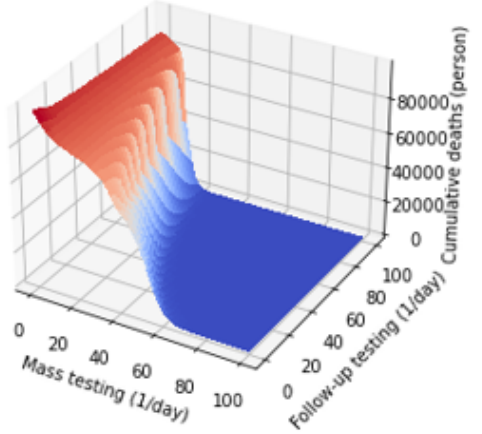

Figure S1: Sensitivity analyses of parameters $b$ and $\boldsymbol{m}$ on the number of cumulative deaths

Simulations were performed with different values of $b$ and $m$. 
medRxiv preprint doi: https://doi.org/10.1101/2021.08.31.21262868; this version posted September 5, 2021. The copyright holder for this preprint (which was not certified by peer review) is the author/funder, who has granted medRxiv a license to display the preprint in perpetuity. It is made available under a CC-BY-NC-ND 4.0 International license .

$a=0.01$

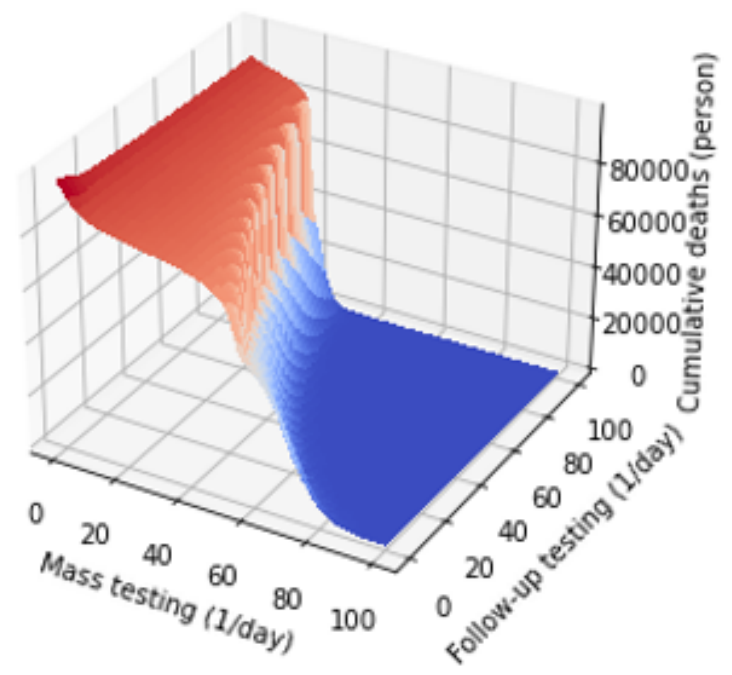

$a=0.1$

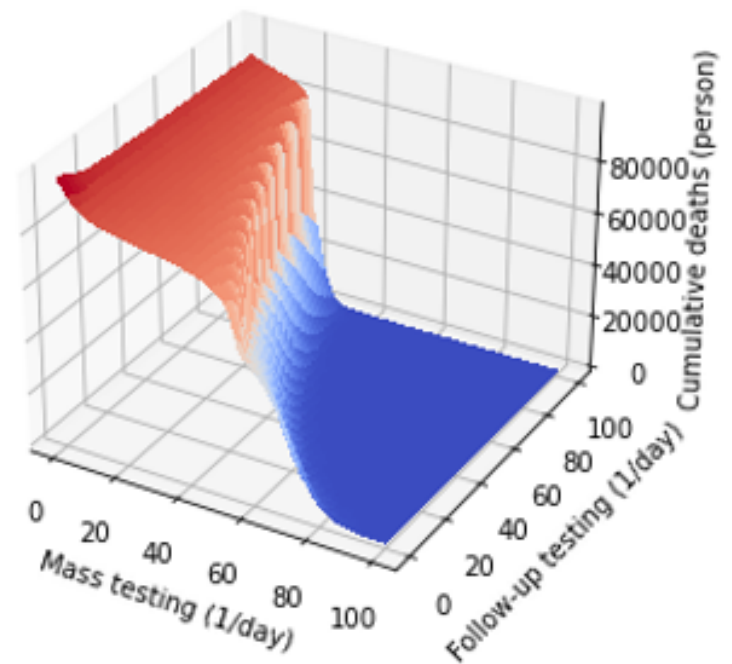

$a=0.03$

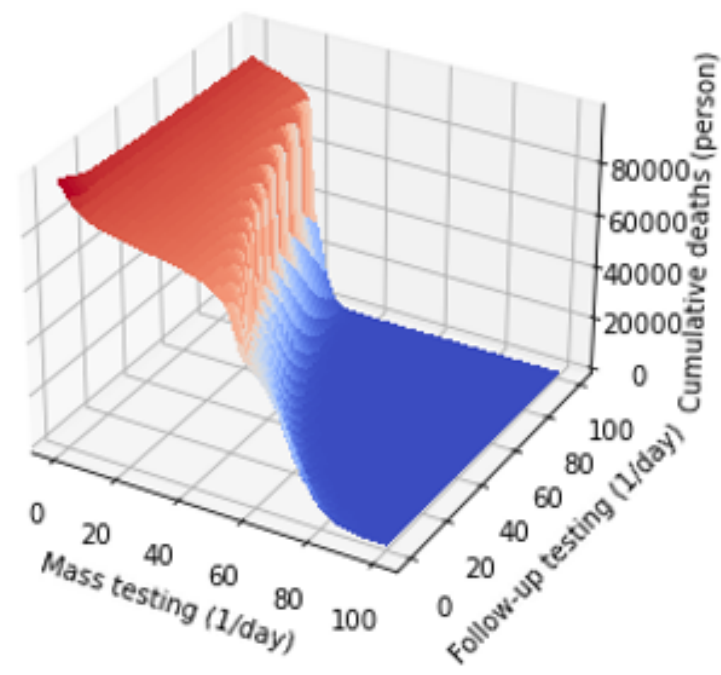

$a=0.3$

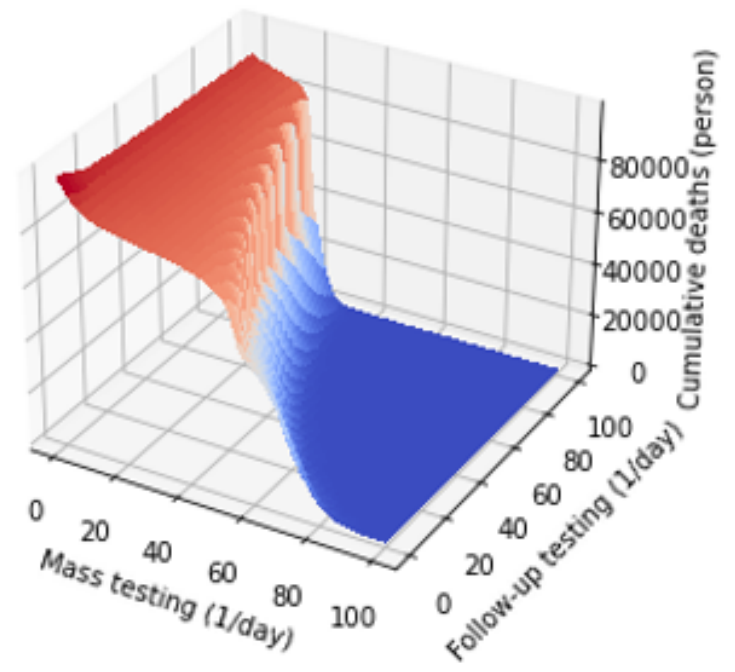

Figure S2: Sensitivity analyses of parameter $a$ on the number of cumulative deaths Simulations were performed with different values of $a$. 